\title{
A Dispersion-Theoretic Account of Taiwanese CV phonotactics
}

\author{
Sheng-Fu Wang \\ New York University
}

\section{Introduction}

Incorporating the notion of contrast in explaining the structure of sound inventories and sound distributions has been an important development in phonological theory. As summed up by Flemming (2004), from the 'Theory of Adaptive Dispersion' (Lindblom, 1986, 1988) to 'Dispersion Theory' (Flemming, 1996, 2002), three functional goals have been assumed to determine the structure of phonological contrasts:

(1) a. Maximise the distinctiveness of contrasts

b. Minimise articulatory effort

c. Maximise the number of contrasts

Flemming's (2004) work formalizes the notion of maximal distinctiveness with constraints on contrasts, and demonstrates that such constraints better explain sound inventories than markedness constraints that evaluate individual sounds. The major difference is that constraints on contrasts capture the generalization that certain contrasts are absent because of a lack of distinctiveness, not because of inherent markedness of the segments in contrast.

In addition to accounting for the structure of inventories, the notion of distinctive contrast has been shown to capture generalization in different phonological phenomena, such as co-occurrence restrictions (Gallagher, 2010) and segmental alternation that preserves phonemic contrasts (Stanton, 2016).

Along this line, this study presents data on the surface phonotactics of voicing and nasality in Taiwanese, and aims to demonstrate that perceptual distinctiveness can provide an account for the distribution of segments, and the configuration of these constraints on contrasts is grounded in language-specific phonetic details, in this case, realization of contrastive vocalic nasality.

Taiwanese has a phonemic nasal contrast in vowels (i.e., pi ${ }^{55}$ 'sad' vs. i $^{55}$ 'side'). The distribution of voiced consonants before vowels is sensitive to vocalic nasality: voiced oral consonants only appear before oral vowels, and nasal consonants only occur before nasal vowels. One way to look at this restriction in distribution is that for voiced consonants, the oral ones (e.g., $/ \mathrm{b} /$ ) and the nasal ones (e.g., $/ \mathrm{m} /$ ) are in complementary distribution. The pattern is shown in (2).

(2) Attested and unattested combinations of voiced onsets and vowels in Taiwanese

$$
\begin{array}{ll}
\text { ba }^{24} \text { 'cat' }{ }^{* m a} & \\
\text { mã } &
\end{array}
$$

This contrasts sharply with French, a language that also has phonemic nasal contrast in vowels, as all four possible combinations of oral/nasal onsets and oral/nasal vowels are attested, as shown in (3).

(3) Attested combinations of voiced onsets and vowels in French (Delvaux et al., 2008)

ba 'low' ma 'my'

bã 'bench' mã '(he) lies'

\footnotetext{
* I am grateful to Gillian Gallagher, Maria Gouskova, Lisa Davidson, Juliet Stanton, Ildi Szabó, Yining Nie, the audience at NYU's PEP Lab, and the audience at AMP 2016 for discussions and comments on this project. All errors are my own.
} 
The Taiwanese data are interesting mainly because they present a case where cross-linguistic differences in the phonetics of nasality correlate with attested surface phonotactics: French and Portuguese, which do not have the gaps in surface phonotactic patterns that Taiwanese have, differ from Taiwanese in having delayed nasalization in nasal vowels (Chang et al., 2011; Delvaux et al., 2008; Parkinson, 1983). I will demonstrate that an analysis with Dispersion Theory is able to connect the phonetic properties and the difference in attested surface phonotactic patterns.

In section 2, I will review studies on nasality in Taiwanese, French, and Portuguese. These studies demonstrate that Taiwanese nasal vowels have a longer nasal portion than the nasal vowels in French and Portuguese. Consequently, I will argue that the co-occurrence restrictions regarding voiced stops and nasal stops in Taiwanese and the lack thereof in French and Portuguese is grounded in this phonetic difference. The framework of analysis is introduced in section 3, and the analysis is presented in section 4 .

\section{Phonetic descriptions of vowel nasality}

Chang et al. (2011) measured airflow in Taiwanese and French nasal vowels. They present their data in two dimensions. 'Percentage of nasal flow volume' is calculated by dividing the volume nasal flow by the total airflow (nasal + flow). 'Percentage of nasalized time', also based on airflow data, is calculated by dividing the nasalized portion in the vowel by the total duration of the vowel. Any value less than $100 \%$ shows delay of nasalization to different extents. The results showed that Taiwanese nasal vowels have a longer nasalized portion than French ones in the CṼ condition (97.1\% vs. 88.3\%), although percentage of nasal airflow volume was lower in Taiwanese nasal vowels than in French ones. The data are shown below (4).

(4) Nasal airflow in Taiwanese and French (Chang et al., 2011)

\begin{tabular}{|c|c|c|}
\hline Taiwanese & \% of nasal flow volume & \% of nasalized time \\
\hline $\mathrm{CV}$ & $56.9 \%$ & $97.1 \%$ \\
\hline $\mathrm{NV}$ & $56.6 \%$ & $99.6 \%$ \\
\hline French & \% of nasal flow volume & $\%$ of nasalized time \\
\hline $\mathrm{CV}$ & $67.7 \%$ & $88.3 \%$ \\
\hline $\mathrm{NV}$ & $75.8 \%$ & $98.8 \%$ \\
\hline
\end{tabular}

The delayed nasalization of nasal vowels in French following a non-nasal onset is also reported in Delvaux et al. (2008). Their aerodynamic data showed that while around $80 \%$ of the instances of nasal vowels had their nasality start at the vocalic onset or even earlier, the trend for vowels following stops was the opposite: around $80 \%$ of the instances of nasal vowels after a stop had delayed nasalization, where nasal airflow started at the $15-20 \%$ point into the vowel. Although the result also indicated that nasalization could start simultaneously with or earlier than the vocalic onset, which was consistent with Cohn's (1990) description, still, these phonetic data showed that French nasal vowels do not consistently have full nasality, especially after stops.

As for Portuguese, there have been studies showing that nasal monophthongs or diphthongs mainly have nasality located in the latter portion of the syllable-nucleus (de Lacerda \& Strevens, 1956; de Lacerda \& Head, 1966; Mateus, 1982; cited in Parkinson, 1983). Parkinson focuses on the issue of whether Portuguese nasal vowels are VN or V $\tilde{V}$ and argued for the latter. In either case, this means that Portuguese nasal vowels do not have full nasal duration.

From these studies, we can see that phonetically, phonemically nasal vowels have longer, almost full, nasal portions in Taiwanese, as opposed to the nasal vowels in French and Portuguese ${ }^{1}$.

In this paper, I will argue that the phonetic fact of full nasalization in Taiwanese is related to the cooccurrence restrictions of voiced consonants and nasals. Especially after voice stops, which already have a weaker burst than voiceless stops, simultaneous or even early velar lowering, for full nasalization in nasal

\footnotetext{
1 The reader may have noticed that the Taiwanese nasal vowels actually do not have full nasalized portion, as the numbers are not $100 \%$. This potentially undermines the hypothesis that stop bursts are weakened by full nasality. However, even following nasal consonants, where carryover nasal co-articulation is supposed to happen, the nasalized portion in nasal vowels is still not $100 \%$. It may suggest that $\mathrm{CV}$ transitions exhibit some prohibiting effect on the measurement of nasal airflow.
} 
vowels, further lowers the air pressure in the vocal tract during stop closure, thereby rendering the burst of voiced stops even weaker. The consequence is that voiced oral stops may be confused with nasal stops before nasal vowels, which, following a Dispersion-Theoretic view, would be the kind of contrasts that tend to be rule out by the principle of contrast maximization.

The preference or even requirement for full nasality also explains another aspect of this phonotactic restriction: there is no vocalic nasal contrast after nasal stops. This restriction can easily derive from the fact that when the onset is a nasal stop, carryover nasalization into an oral vowel is obligatory. If the requirement of full nasalization is understood as a requirement of a full oral-nasal contrast, the partially nasalized oral vowel is also not contrastive enough with the phonemically nasal vowel.

In other words, the requirement of a full oral-nasal contrast, derived from phonetic and perceptual data, can be used to account for the co-occurrence restrictions of oral voiced stops and nasal vowels on the one hand, and of nasal stops and oral vowels on the other. I will formalize these restrictions in terms of constraints on contrasts later in this paper.

\section{Framework of Analysis}

Deriving an underlying inventory with the interplay of constraints like MINDIST and MAXIMISE CONTRASTS is straightforward. However, deriving sound inventories in a context-free way is not the only task that contrastive constraints can do. As shown by Flemming (2002, 2004), MINDIST and MAXIMISE CONTRASTS are able to interact with other markedness constraints to derive well-formed words in a language. That is, such interactions should also be able to derive context-sensitive neutralization, the kind of phenomena discussed in Steriade $(1997,1999)$ in terms of cue licensing.

However, Flemming (2006) discusses a major problem of such 'free interaction': it predicts unattested patterns, especially 'contextual enhancement', which refers to the re-organization of sound inventory based on some specific phonological environment. He mentioned the case of front vowel neutralization in Cantonese, which I will briefly repeat here.

In Cantonese, the contrast of roundedness between front vowels $/ \mathrm{i} /$ and $/ \mathrm{y} /$ is neutralized after labial onsets (Yip, 1988). The contrast between /i/ and / $/$ / is modeled by not violating the MINDIST=F2:2 OR F3:2 constraint based on the following scales:

(5) Scales of vowel perceptibility (Flemming 2006, p. 10)

\begin{tabular}{cccccc} 
F2: & 5 & 4 & 3 & 2 & 1 \\
\hline & i & y & $\dot{\mathrm{i}}$ & $\mathrm{u}$ & $\mathrm{u}$ \\
F3: & 4 & 3 & 2 & 1 & \\
\hline & $\mathrm{i}$ & $\dot{\mathrm{i}}$ & $\mathrm{y}, \mathrm{u}$ & $\mathrm{I}$ &
\end{tabular}

After labial onsets, obligatory labial co-articulation obscures the F3 distinction between /i/ and /y/, which is modeled by the following scales.

(6) Scale of vowel perceptibility with labialized vowels (Flemming 2006, p. 12)

\begin{tabular}{cccccc} 
F2: & 5 & 4 & 3 & 2 & 1 \\
\hline & $\mathrm{i}$ & $\mathrm{y}$ & $\dot{\mathrm{i}}$ & $\mathrm{u}$ & $\mathrm{u}$ \\
& & & & & \\
F3: & 4 & 3 & 2 & 1 & \\
\hline & $\mathrm{i}$ & $\dot{\mathrm{i}}$ & $\mathrm{y}, \mathrm{u}$ & $\mathrm{I}$ & \\
& & $\mathrm{i}^{\beta}$ & $\mathrm{i}^{\beta}$ & &
\end{tabular}

This would make the segment inventory containing both $/ \mathrm{i} /$ and $/ \mathrm{y} /$ violate MINDIST=F2:2 OR F3:2. However, when we allow free interaction of MINDIST and MAXIMIZE CONTRAST constraints with other markedness constraints, instead of neutralization front vowels and a shrinkage of segmental inventory in the labial context, we actually get the emergence of central vowels, which is unattested: 
(7) Tableau from (Flemming 2006, p. 15)

\begin{tabular}{|c|c|c|c|c|}
\hline & LABIALCOART. & $\mathrm{MD}=\mathrm{F} 2: 2$ OR F3:3 & MAXCONTRASTS & $\mathrm{MD}=\mathrm{F} 2: 2$ OR F3:2 \\
\hline a. pi, py, pu & $* !$ & & $\checkmark \checkmark \checkmark$ & $*$ \\
\hline b. $\mathrm{pi}^{\beta}, \mathrm{py}, \mathrm{pu}$ & & $* !$ & $\checkmark \checkmark \checkmark$ & $*$ \\
\hline 胭㲾 c. $\mathrm{pi}^{\beta}, \mathrm{pi}^{\beta}, \mathrm{pu}$ & & $*$ & $\checkmark \checkmark \checkmark$ & $* *$ \\
\hline d. pi, pu & & & $\checkmark \checkmark !$ & \\
\hline
\end{tabular}

To remedy this problem, Flemming (2006) proposes a constrained implementation of Dispersion-Theoretic constraints. The architecture of grammar is broken down into three steps: Inventory Selection, Phonetic Realization, and Evaluation of Surface Contrasts (ESC). Mindist and MAXIMIZE CONTRAST play important roles in Inventory Selection. In Phonetic Realization, the interplay of faithfulness constraints and markedness constraints based on factors such as articulatory efforts derive the optimal phonetic realizations of sounds form the inventory. Finally, Mindist and the constraint *MERGE, which punishes neutralization, evaluate surface contrasts. Using *MERGE instead of MAXIMIZE CONTRAST reflects that it is impossible to enhance contrasts by re-organize the sound inventory in a certain context. Details of his analysis are presented in the following tableaux. The selection of the sounds in the inventory is presented in (8), where the ranking of MAXCONTRASTS with respect of the MINDIST constraints determine the phonemic inventory of the language. The realization of these segments in combination is detailed by analysis in (9), where interactions between a constrain regarding coarticulation interacts with IDENT constraints. The gist of the analysis is at the stage of Evaluation of Surface Contrasts, shown in (10), where realization of underlying representations does not alter anymore, and no contrast can be added. The only possible candidates contain the faithful inventory (and its realization), as well as the inventories containing neutralization.

(8)

Inventory Selection in Cantonese high vowels (Flemming 2006, p. 11)

\begin{tabular}{|c||c|c|c|c|}
\hline & MD=F2:2 OR F3:2 & MAXCONTRASTS & MD=F2:2 OR F3:3 & MD=F2:4 \\
\hline \hline a. i, i, u & & $\checkmark \checkmark \checkmark$ & $* * !$ & $* *$ \\
\hline b. $\mathrm{i}, \mathrm{y}, \mathrm{u}$ & & $\checkmark \checkmark \checkmark$ & $*$ & $* *$ \\
\hline c. i, $\mathrm{y}, \mathrm{i}, \mathrm{u}$ & $* !$ & $\checkmark \checkmark \checkmark \checkmark$ & $* * *$ & $* * * * *$ \\
\hline d. i, $\mathrm{y}, \mathrm{u}, \mathrm{u}$ & $* !$ & $\checkmark \checkmark \checkmark \checkmark$ & $* * *$ & $* * * * *$ \\
\hline e. i, u & & $\checkmark \checkmark !$ & & \\
\hline
\end{tabular}

(9) Phonetic Realization (Modified from Flemming 2006, p. 14)

\begin{tabular}{|c|c|c|c|}
\hline /pin/ & *LABIALCOARTICULATION & IDENT(F2) & IDENT(F3) \\
\hline a. pin & $* !$ & & \\
\hline 实 b. $\mathrm{pi}^{\beta} \mathrm{n}$ & & & * \\
\hline c. $\mathrm{pi}^{\beta} \mathrm{n}$ & & $* * !$ & $* * *$ \\
\hline
\end{tabular}

(10) Evaluation of Surface Contrasts (Modified from Flemming 2006, p. 14)

\begin{tabular}{|l||c|c|c|c|}
\hline$/$ pyn, pin, pun/ & MD=F2:2 OR F3:2 & *MERGE & MD=F2:2 OR F3:3 & MD=F2:4 \\
\hline \hline a. pyn, $\mathrm{pi}^{\mathrm{\beta}} \mathrm{n}, \mathrm{pun}$ & $* !$ & & $*$ & $* *$ \\
\hline b. $\mathrm{pi}^{\mathrm{\beta}} \mathrm{n}, \mathrm{pun}$ & & $*$ & & \\
\hline c. pyn, pun & & $*$ & & $* !$ \\
\hline
\end{tabular}

\section{Analysis}

The goal of the analysis is to derive the different surface patterns for languages like Taiwanese on one hand and languages like French on the other. Specifically, the analysis will follow from the hypothesis that the difference in surface phonotactics is driven by a crucial phonetic difference regarding the realization of nasality in vowels. 
4.1 Inventory Selection I propose the following perceptibility scales for stops, shown in (11). There is one scale for the oral context and one for the nasal context. In both of the scales, the distance between voiced stops are closer than between voice stops. In the nasal context, the distance between the voiced stops is even closer, as voicing is supposed to weaken the burst of the stop release. I also assume that NṼ coarticulation will always give a nasal stop a nasal 'context' following it. I propose a corresponding MINDIST=BURST constraint to evaluate the distinctiveness of contrast between stops in the inventory.

(11) The stop burst/release perceptibility scale:

\begin{tabular}{cccccccc}
$\mathrm{m}^{\tilde{a}}$ & $\mathrm{~b}^{\mathrm{a}}$ & $\mathrm{p}^{\mathrm{a}}$ & $\mathrm{p}^{\mathrm{ha}}$ & $\mathrm{m}^{\tilde{\mathrm{a}}}$ & $\mathrm{b}^{\tilde{\mathrm{a}}}$ & $\mathrm{p}^{\tilde{\mathrm{a}}}$ & $\mathrm{p}^{\mathrm{ha}}$ \\
\hline 1 & 3 & 6 & 10 & & 2 & 5 & 9
\end{tabular}

(12) MINDIST=BURST:X: Assign a violation to a contrast whose distance on the perceptibility scale for burst is less than $\mathrm{x}$.

In inventory selection, the scales for the oral and the nasal contexts are averaged, which gives the scale in (13) for both Taiwanese and French.

(13) The stop burst/release perceptibility scale for inventory selection:

\begin{tabular}{cccc}
$\mathrm{m}$ & $\mathrm{b}$ & $\mathrm{p}$ & $\mathrm{p}^{\mathrm{h}}$ \\
\hline 1 & 2.5 & 5.5 & 9.5
\end{tabular}

When MAXIMIZE CONTRAST is ranked between two MINDIST:BURST constraints, we derive the inventory where nasal stops and oral voiced stops are contrastive. The tableau of analysis is given in (14), which is again the same for both Taiwanese and French.

(14) Inventory Selection for voiced stops in Taiwanese and French: MD=BURST:1.5 $\gg$ MAXIMIZE CONTRAST $\gg$ MD=BURST: 4

\begin{tabular}{|c||c|c|c|}
\hline & MD=BURST: 1.5 & MAXIMIZE CONTRASTS & MD=BURST:4 \\
\hline \hline a. $\{\mathrm{m}, \mathrm{b}\}$ & & $\checkmark \checkmark$ & $*$ \\
\hline b. $\{\mathrm{m}\}$ & & $\checkmark ! \mathrm{W}$ & $\mathrm{L}$ \\
\hline
\end{tabular}

4.2 Phonetic Realization The categories of stops from Inventory Selection are used as inputs at the stage of Phonetic Realization. The outputs will be phonetic forms. I propose the following constraints for analysis at this stage:

(15) Align(NAs, EdGE, V): Assign a violation to a nasal vowel whose nasality does not align with both edges of the vowel

(16) $\mathrm{N}^{\tilde{V}} \mathrm{~V}$ : Assign a violation to a sequence of nasal onset and oral vowel without nasal coarticulation at the onset of the vowel ${ }^{2}$

(17) $\mathrm{D}^{\mathrm{V}} \tilde{\mathrm{V}}$ : Assign a violation to a sequence of oral onset and nasal vowel without an oral portion at the onset of the vowel

(18) $\operatorname{MAx}[ \pm$ NASAL]: Assign a violation to total assimilation/alternation between oral and nasal segments

For both Taiwanese and French, the syllable types from the phonemic inventory are the following: /ba/, /bã/, $/ \mathrm{ma} /$, and /mã/. I will first focus on $/ \mathrm{bã} /$ and $/ \mathrm{ma} /$, where the nasality of the onset and the vowel do not agree. These are also the syllable types that are not attested on the surface in Taiwanese.

I propose that the phonetic realization of the unattested /bã/ is inferred from the attested surface patterns for $\left[p^{\tilde{a}} \tilde{a}\right]$ and $\left[p^{\text {hãa }} \tilde{a}\right.$ : the nasal vowel would be realized with full nasality (c.f. Chang et al. 2011). For the present analysis, the ALIGN(NAS, EDGE, V) constraint is ranked above $\mathrm{D}^{\mathrm{V}} \tilde{\mathrm{V}}$ to derive this particular way of nasal realization so that the winner is $\mathrm{b}^{\tilde{a}} \tilde{\mathrm{a}}$, as shown in (19).

2 It is motivated by research showing that carryover nasal co-articulation occurs across languages and may be partly physiological (Ushijima \& Hirose, 1974; Clumeck, 1976; Flege, 1988) 
(19)

Phonetic Realization of / bã/ in Taiwanese

\begin{tabular}{|c|c|c|c|c|}
\hline bã & $\mathrm{N}^{\tilde{V}} \mathrm{~V}: \operatorname{MAX}[+\mathrm{NASAL}]$ & Align(NAS, EdGE, V) & MAX[-NASAL] & $\mathrm{D}^{\mathrm{V}} \tilde{\mathrm{V}}$ \\
\hline 誽 $\mathrm{a} \cdot \mathrm{b}^{\tilde{a}} \tilde{\mathrm{a}}$ & 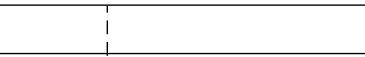 & | & & $*$ \\
\hline b. $b^{a} \tilde{a}$ & i & $* ! \mathrm{W}$ & & $\mathrm{L}$ \\
\hline c. ba & $* ! \mathrm{W}$ & i & & $\mathrm{L}$ \\
\hline d. $\mathrm{m}^{\tilde{a}} \tilde{a}$ & 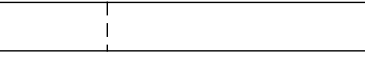 & i & $* ! \mathrm{W}$ & $\mathrm{L}$ \\
\hline
\end{tabular}

As for French, I propose that the Align(NAS, EDGE, V) constraint is ranked below $\mathrm{D}^{\mathrm{V}} \tilde{\mathrm{V}}$, so that the realization of nasal vowel with a delay in nasality is chosen as the phonetic output. The analysis is shown in (20).

Phonetic Realization of /bã/ in French

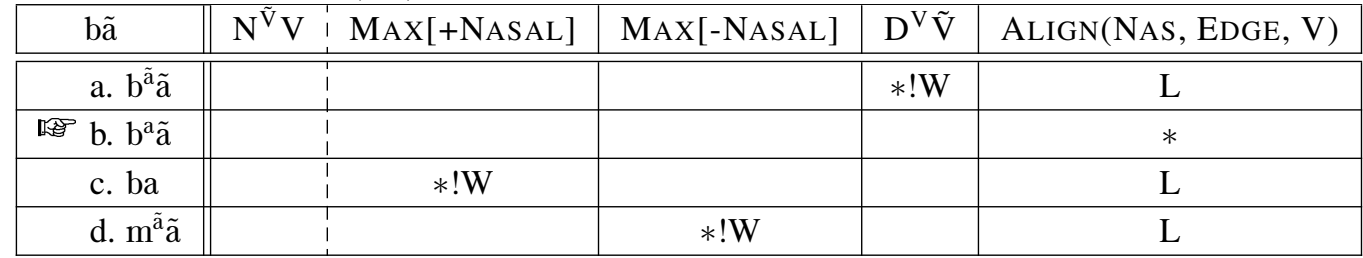

I now turn to $/ \mathrm{ma} /$, which is also unattested on the surface in Taiwanese but attested in French. The full analysis is shown in (21). I propose that the realization in Taiwanese would be [m $\left.{ }^{\tilde{a}} \tilde{a}\right]$ (21a), with the force

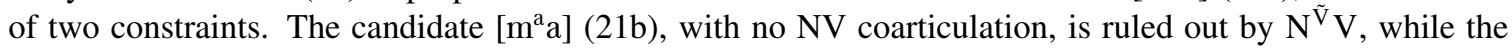
candidate $\left[\mathrm{m}^{\tilde{a}} \mathrm{a}\right](21 \mathrm{c})$ is ruled out by ALIGN(NAS, EDGE, V), as the nasality does not align with the right edge of the vowel.

(21) Phonetic Realization of $/ \mathrm{ma} /$ in Taiwanese

\begin{tabular}{|c|c|c|c|c|}
\hline $\mathrm{ma}$ & $\mathrm{N}^{\mathrm{V} V} \mathrm{~V}: \mathrm{MAX}[+\mathrm{NASAL}]$ & ALIGN(NAS, EDGE, V) & MAX[-NASAL] & $\mathrm{D}^{\mathrm{V}} \tilde{\mathrm{V}}$ \\
\hline 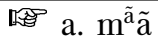 & 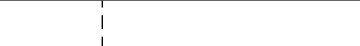 & & * & \\
\hline b. $\mathrm{m}^{\mathrm{a}} \mathrm{a}$ & $* ! \mathrm{W}$ & & $\mathrm{L}$ & \\
\hline c. $\mathrm{m}^{\tilde{a}} \mathrm{a}$ & i & $* ! \mathrm{W}$ & $\mathrm{L}$ & \\
\hline d. ba & $* ! \mathrm{W}$ & & $\mathrm{L}$ & \\
\hline
\end{tabular}

For the French /ma/, as shown in (22), ranking ALIGN(NAS, EDGE, V) below all other constraints makes $\left[\mathrm{m}^{\tilde{a}} \mathrm{a}\right](22 \mathrm{c})$ the winner, as full nasality is not required, and the candidate [ $\left.\mathrm{m}^{\tilde{a}} \tilde{a}\right](22 \mathrm{a})$, where the oral vowel is completely nasalized, is ruled out by MAX[-NASAL].

Phonetic Realization of /ma/ in French

\begin{tabular}{|c|c|c|c|c|}
\hline $\mathrm{ma}$ & $\begin{array}{l:l}\mathrm{N}^{\tilde{V}} \mathrm{~V} & \mathrm{MAX}[+\mathrm{NASAL}] \\
\end{array}$ & MAX[-NASAL] & $\mathrm{D}^{\mathrm{V}} \tilde{\mathrm{V}}$ & Align(NAS, EDGE, V) \\
\hline a. $\mathrm{m}^{\tilde{a}} \tilde{\mathrm{a}}$ & 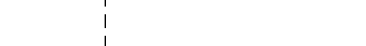 & $* ! \mathrm{W}$ & & $\mathrm{L}$ \\
\hline b. $\mathrm{m}^{\mathrm{a}} \mathrm{a}$ & $* ! \mathrm{W}$ & & & $\mathrm{L}$ \\
\hline c. $\mathrm{m}^{\tilde{\mathrm{a}} \mathrm{a}}$ & $\begin{array}{ll} \\
1\end{array}$ & & & * \\
\hline d. ba & 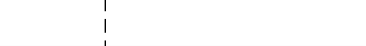 & $* ! \mathrm{W}$ & & $\mathrm{L}$ \\
\hline
\end{tabular}

For both languages, the faithful realization of the surface-attested combination of oral stop and oral vowel, $/ \mathrm{ba} /$, is derived primarily by preventing the oral segments turning into nasal ones. In particular, the oral vowel is prevented from turning into nasal by both MAX[-NASAL], which eliminates the candidate with a full nasal vowel, and Align(NAS, EDGE, V), which eliminates the candidate a partially nasalized vowel. 
(23)

Phonetic Realization of / ba/ in Taiwanese

\begin{tabular}{|c|c|c|c|c|}
\hline $\mathrm{ba}$ & $\mathrm{N}^{\tilde{V}} \mathrm{~V}: \mathrm{MAX}[+\mathrm{NASAL}]$ & Align(NAS, EDGE, V) & MAX[-NASAL] & $\mathrm{D}^{\mathrm{V}} \tilde{\mathrm{V}}$ \\
\hline a. $b^{\mathrm{a} a}$ & 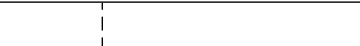 & & & \\
\hline b. $b^{\tilde{a}} \tilde{a}$ & 1 & & $* ! \mathrm{W}$ & \\
\hline c. $b^{\mathrm{a}} \tilde{\mathrm{a}}$ & 1 & $* ! \mathrm{W}$ & & \\
\hline
\end{tabular}

(24)

Phonetic Realization of / ba/ in French

\begin{tabular}{|c|c|c|c|c|}
\hline ba & $\mathrm{N}^{\tilde{V}} \mathrm{~V}: \operatorname{MAX}[+\mathrm{NASAL}]$ & MAX[-NASAL] & $\mathrm{D}^{\mathrm{V}} \tilde{\mathrm{V}}$ & Align(NAS, EDGE, V) \\
\hline 啰 & 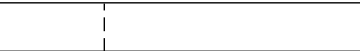 & & & \\
\hline b. $b^{\tilde{a}} \tilde{a}$ & i & $* ! \mathrm{W}$ & & \\
\hline c. $b^{a} \tilde{a}$ & 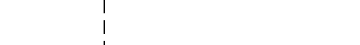 & & & $* ! \mathrm{W}$ \\
\hline
\end{tabular}

As for another input that has a faithful output, /mã/, the output with a fully nasalized vowel is derived by eliminating the candidate with a partially nasalized vowel with ALIGN(NAS, EDGE, V) and the candidate with an oral vowel by $\mathrm{N}^{\tilde{V}} \mathrm{~V}$. The analysis for both languages are shown in (25) and (26).

Phonetic Realization of /mã/ in Taiwanese

\begin{tabular}{|c|c|c|c|c|}
\hline mã & $\mathrm{N}^{\mathrm{V} V} \mathrm{~V}: \mathrm{MAX}[+\mathrm{NASAL}]$ & Align(NAs, EdGE, V) & MAX[-NASAL] & $\mathrm{D}^{\mathrm{V}} \tilde{\mathrm{V}}$ \\
\hline 嘫 $\mathrm{a} \cdot \mathrm{m}^{\tilde{\mathrm{a}}} \tilde{\mathrm{a}}$ & 1 & 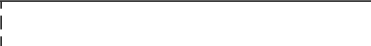 & & \\
\hline b. $\mathrm{m}^{\tilde{a}} \mathrm{a}$ & I & $* \mathrm{~W}$ & & \\
\hline c. $m^{\mathrm{a} a}$ & $* ! \mathrm{W}$ & 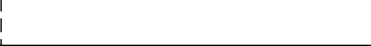 & & \\
\hline
\end{tabular}

(26) Phonetic Realization of /mã/ in French

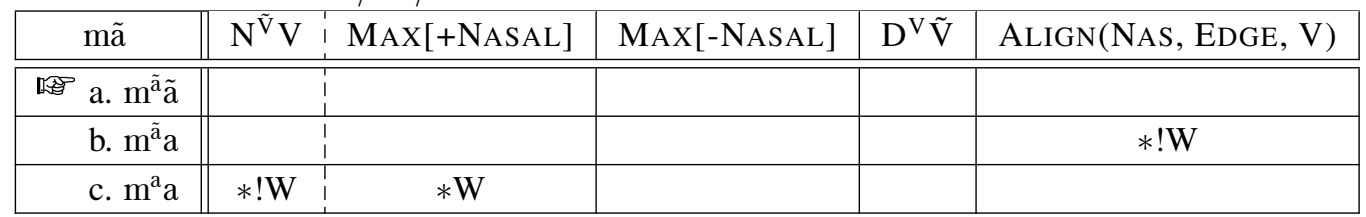

To summarize, the Phonetic Realization stage gives Taiwanese and French the phonetic outputs shown in (27).

(27) Inputs and outputs for Phonetic Realization

\begin{tabular}{c|cccc} 
inputs & ba & bã & ma & mã \\
\hline output for Taiwanese & ba & $b^{\tilde{a}} \tilde{a}$ & $m^{\tilde{a}} \tilde{a}$ & $m^{\tilde{a}} \tilde{a}$ \\
outputs for French & ba & $b^{\mathrm{a}} \tilde{a}$ & $\mathrm{~m}^{\tilde{a}} \mathrm{a}$ & $\mathrm{m}^{\tilde{a}} \tilde{a}$
\end{tabular}

4.3 Evaluation of Surface Contrasts The outputs of Phonetic Realization are evaluated based on their distinctiveness from each other in this stage. The same stop distinctiveness scales for the MINDIST=BURST constraints are repeated in (28), and the constraint rankings are identical with what was used in Inventory Selection, except for MAXIMIZE CONTRAST being replaced by *MERGE (Flemming, 2006), which penalizes merger from input. As mentioned earlier, the difference between MAXIMIZE CONTRAST and *MERGE reflects a constrained implementation of distinctiveness constraints: in the Evaluation of Surface Contrasts, no new contrasts can be added, thus merger is the only allowed operation in GEN.

(28) The stop burst/release perceptibility scale:

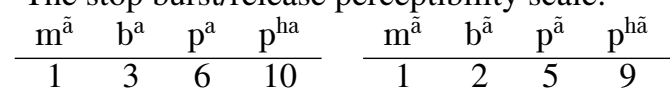


For Taiwanese onset stops in the nasal context, the surface inventory without merger (candidate c in (29)) fails to be the winner, as the distance between $\mathrm{m}^{\tilde{\mathrm{a}}}$ and $\mathrm{b}^{\tilde{\mathrm{a}}}$ is less than 1.5. As for the two candidates with either $m^{\tilde{a}} \tilde{a}$ or $b^{\tilde{a}} \tilde{a}$ instead of the other one, candidate a, i.e., $\left\{m^{\tilde{a}} \tilde{a}, p^{\tilde{a}} \tilde{a}, p^{h \mathfrak{a}} \tilde{a}\right\}$, wins over the competitor when evaluated against the MINDIST=BURST: 4 constraint, as $\mathrm{m}^{\tilde{\tilde{a}}}$ and $\mathrm{p}^{\tilde{a}}$ are further apart than $\mathrm{m}^{\tilde{a}}$ and $\mathrm{b}^{\tilde{\mathrm{a}}}$ on the scale.

Taiwanese: nasal context

\begin{tabular}{|c|c|c|c|}
\hline$\left\{\mathrm{m}^{\tilde{a}} \tilde{\mathrm{a}}, \mathrm{b}^{\tilde{a}} \tilde{\mathrm{a}}, \mathrm{p}^{\tilde{a}} \tilde{\mathrm{a}}, \mathrm{p}^{\mathrm{h} \tilde{a}} \tilde{\mathrm{a}}\right\}$ & MD=BURST: 1.5 & *MERGE & MD=BURST: 4 \\
\hline a. $\left\{\mathrm{m}^{\tilde{a}} \tilde{a}, \mathrm{p}^{\tilde{a}} \tilde{a}, \mathrm{p}^{\mathrm{h} \tilde{a}} \tilde{a}\right\}$ & & $*$ & \\
\hline b. $\left\{b^{\tilde{a}} \tilde{a}, p^{\tilde{a}} \tilde{a}, p^{h a ̃ a}\right\}$ & & $\mathrm{L}$ & $* \mathrm{~W}$ ! \\
\hline c. $\left\{\mathrm{m}^{\tilde{\mathrm{a}}} \tilde{\mathrm{a}}, \mathrm{b}^{\tilde{a}} \tilde{\mathrm{a}}, \mathrm{p}^{\tilde{a}} \tilde{\mathrm{a}}, \mathrm{p}^{\mathrm{h}} \tilde{\mathrm{a}} \tilde{\mathrm{a}}\right\}$ & $* ! \mathrm{W}$ & $\mathrm{L}$ & $* \mathrm{~W}$ \\
\hline
\end{tabular}

For French, the fully faithful inventory is chosen as the winner, as [ $\left.\mathrm{b}^{\mathrm{a}} \mathrm{a}\right]$, the realization for $/ \mathrm{b} \tilde{a} /$, does not incur a violation of the MINDIST=BURST: 1.5 constraint, since the distance between $m^{\tilde{a}} \tilde{a}$ and $b^{a} \tilde{a}$ is evaluated with the scale for the oral context and the distance between them is bigger than 1.5 in that scale. The analysis is shown in (30).

French: nasal context

\begin{tabular}{|c||c|c|c|}
\hline$\left\{\mathrm{m}^{\tilde{a}} \tilde{\mathrm{a}}, \mathrm{b}^{\mathrm{a}} \tilde{\mathrm{a}}, \mathrm{p}^{\tilde{a}} \tilde{\mathrm{a}}\right\}$ & MD=BURST:1.5 & *MERGE & MD=BURST:4 \\
\hline \hline a. $\left\{\mathrm{m}^{\tilde{\mathrm{a}}} \tilde{\mathrm{a}}, \mathrm{p}^{\tilde{a}} \tilde{\mathrm{a}}\right\}$ & & $* ! \mathrm{W}$ & $\mathrm{L}$ \\
\hline b. $\mathrm{b} \cdot\left\{\mathrm{m}^{\tilde{\mathrm{a}}} \tilde{\mathrm{a}}, \mathrm{b}^{\mathrm{a}} \tilde{\mathrm{a}}, \mathrm{p}^{\tilde{\tilde{a}}} \tilde{\mathrm{a}}\right\}$ & & & $* \mathrm{~W}$ \\
\hline
\end{tabular}

In the oral context, for both languages, the inventories without merger are chosen as winners. The analyses can be seen in (31) and (32).

Taiwanese: oral context

\begin{tabular}{|c|c|c|}
\hline$\left\{b^{\mathrm{a} a}, \mathrm{p}^{\mathrm{a} a}, \mathrm{p}^{\mathrm{ha}} \mathrm{a}\right\}$ & MD=BURST: $1.5: *$ MERGE & MD=BURST: 4 \\
\hline 栥 a. $\left\{b^{\mathrm{a}} \mathrm{a}, \mathrm{p}^{\mathrm{a}} \mathrm{a}, \mathrm{p}^{\mathrm{ha}} \mathrm{a}\right\}$ & 1 & \\
\hline b. $\left\{p^{a} a, p^{\text {ha }} a\right\}$ & $* ! \mathrm{W}$ & \\
\hline
\end{tabular}

French: oral context

\begin{tabular}{|c||c:c|c|}
\hline$\left\{\mathrm{m}^{\tilde{a}} \mathrm{a}, \mathrm{b}^{\mathrm{a}} \mathrm{a}, \mathrm{p}^{\mathrm{a}} \mathrm{a}\right\}$ & MD=BURST: 1.5 & $*$ MERGE & MD=BURST:4 \\
\hline \hline a. $\left\{\mathrm{m}^{\tilde{a}} \mathrm{a}, \mathrm{b}^{\mathrm{a}} \mathrm{a}, \mathrm{p}^{\mathrm{a}} \mathrm{a}\right\}$ & & & $*$ \\
\hline b. $\left\{\mathrm{b}^{\mathrm{a}} \mathrm{a}, \mathrm{p}^{\mathrm{a}} \mathrm{a}\right\}$ & & $* ! \mathrm{W}$ & $\mathrm{L}$ \\
\hline
\end{tabular}

4.4 The segments that are not stops So far, the analysis has centralized on stops. However, there are some other segments that participate in this restriction. I start with the alveolar lateral /l/. With the absence of an alveolar voiced stop in Taiwanese, this sound is often categorized in the voiced stop series (Pan, 2004). However, it is still transcribed and described as $/ \mathrm{l} /$ rather than as $/ \mathrm{d} /$.

Like voiced stops, /l/ is also absent before nasal vowels. Does the participation of this non-obstruent undermine the analysis based on stop contrast? I would argue that based on the acoustic properties of laternals, they should be more confusable with nasals than voiced stops are. The acoustics of laterals and nasals have one thing in common: they both have anti-formants caused by having 'side branches' in their articulatory configurations. Coupled with the fact that laterals, unlike obsturents, do not have closure and release that introduce 'modulation' to aid perception. (c.f. Henke et al. 2012; Kawasaki-Fukumori \& Ohala 1997), [ $\left[1^{\tilde{a}} \tilde{a}\right]$ would be more confusable with [nãa $\left.\tilde{a}\right]$ than [d $\left.{ }^{\tilde{a}} \tilde{a}\right]$ (if it existed in Taiwanese).

A more problematic case is the voiced fricative /z/, sometimes transcribed as an affricate /dz/ or /dz/ (Lin, 2015). This sound is also absent before nasal vowels. Following the Dispersion-Theoretic analysis that I developed so far, the the frication noise should make it distinguishable from nasals, so that [ $\left.\mathrm{z}^{\tilde{a}} \tilde{a}\right]$ should be a viable surface form. 
I offer two possibilities to account for the problem of *zã $\tilde{a}$. The first possibility is saying that this is becoming less of a problem because of an undergoing sound change: / $\mathrm{z} /$ is changing primarily into /1/ and in some marginally cases into /g/ (Ang, 2012). Ang, citing Maddieson \& Disner (1984), explains the sound change and thus the disappearance of $/ z /$ in Taiwanese by what he termed 'pattern congruity effect': unlike $/ \mathrm{s} /$, which is phonemically contrastive with the affricate /ts/, /z/ does not have an affricate counterpart (or the other way around, if $/ \mathrm{z} /$ is transcribed as the affricate $/ \mathrm{dz} /$ ). Also, unlike stops, which contain three categories in terms of places of articulation, only alveolar fricatives exist in Taiwanese. Ang uses these two facts to argue that it makes /z/ prone to disappear because its disappearance would not affect a series of sounds. He implicitly uses the notion of natural class in provide a case whether sound change would face resistance: devoicing of voiced bilabial stops would also trigger devoicing of other stops, thus is less likely to happen. For the purpose of this squib, the sound change seems to suggest that sound changes is resulting in patterns that are more phonetically grounded, which may be tangentially related to Ang's claim about the structure of sound inventory.

Another possible explanation is that since the majority of the sound types in the co-occurrence restriction are stops, the language learner may generalize the patterns in voiced stops, grounded in phonetic and perceptual properties, to the whole class of voiced obstruents.

4.5 Alternative (Standard) Analysis This subsection explores a 'standard' analysis of the typological differences between Taiwanese and French. Such an analysis may uses three constraints as the following. Different rankings of these three constraints can yield Taiwanese-, French-, and English-type languages, as shown in (36).

AGREE[NASAL]: assign one violation to a syllable where the onset and the vowel differ in nasality.

(34) IDENT[NASAL]: assign one violation when one segment from the input changes its nasal feature value in the output.

$* \tilde{\mathrm{V}}$ : assign one violation to a nasal vowel.

(36) a. Agree[NASAL $] \gg\{* \tilde{\mathrm{V}}$, Ident[NASAL] $\}$ : ba, mã (Taiwanese)

b. Ident[NASAL] $\gg\{$ Agree[NASAL], *Ṽ $\}:$ ba, bã, ma, mã (French, Portuguese)

c. $* \tilde{\mathrm{V}} \gg\{$ Ident $[\mathrm{NASAL}]$, Agree[NASAL] $\}:$ ba, ma (English)

This analysis has the advantage of capturing typological differences in a straightforward way. However, there are two reasons why I believe the Dispersion Theoretic account should be preferred. First, for this analysis, additional machinery is needed regarding AGReE[NASAL], as this constraint only applies to voiced stops (i.e., [pã] is attested in Taiwanese). The proposed Dispersion Theoretic account solves this by using the incorporating perceptual distance between different types of stops.

The second, and perhaps more important, reason for not preferring this analysis is that the relationship between phonotactics and phonetics is not explicit. In other words, this analysis does not say anything about the phonetic realizations of the nasal vowels, and thus is not available to connect the seemingly existent relationship between Taiwanese and French, which is the focus of my Dispersion Theoretic analysis.

\section{Discussion \& Conclusion}

The proposal in this paper aims to capture the assumption that the difference in surface phonotactics of voicing and nasality between languages like Taiwanese and French is correlated to the phonetics of nasal vowels. This is done by using a three-stage framework of Dispersion Theory, where Phonetic Realization is a distinct stage that has consequences on how the attested surface forms look like.

For the present analysis, this framework allows us to locate the cross-linguistic difference between Taiwanese and French in Phonetic Realization, which has some support in the literature (Chang et al., 2011; Delvaux et al., 2008; Parkinson, 1983), while keeping other components of the grammar the same. The difference in phonetic realization is formalized with the different ranking of an alignment constraint constraint 
on nasality, relative to other constraints. And the previous section has shown how this analysis is able to derive the different surface phonotactics in these two types of languages.

This proposal makes specific predictions concerning the typology of the interaction between nasality and voicing, as shown in (37). The upper two cells are Taiwanese- and French- type languages respectively. The lower cells predict that for languages without voiced oral stops on the surface, there will be languages that allow and disallow a contrast of vocalic nasality after a nasal onset.

Typological predictions
\begin{tabular}{l|c|c} 
& \multicolumn{2}{|c}{ Align(Nas, Edge, V) } \\
\hline & high-ranked & low-ranked \\
\hline MD=BURST:1.5: b,m & ba, ${ }^{*}$ bã, ${ }^{*}$ ma, mã & ba, bã, ma, mã \\
\hline MD=BURST:2: m & ${ }^{\text {ba }}$ *bã, ${ }^{*}$ ma, mã & ${ }^{*}$ ba, ${ }^{*}$ bã, ma, mã
\end{tabular}

This proposal also makes very specific predictions on the perception of the $/ \mathrm{b} /-/ \mathrm{m} /$ contrast (as well as in other places of articulation) cross-linguistically: The difference between Taiwanese and French-like languages only lies in phonetic realizations, and the different phonetic realizations are channeled through the same perceptual process (Evaluation of Surface Contrast) to result in different surface phonotactics. This predicts that given the same phonetic form, regardless of the surface phonotactics of the native language, the speakers would have the same perception. More specifically, it predicts that Taiwanese speakers should also be able to tell $\left[b^{a} \tilde{a}\right]$ from [ $\left.m^{\tilde{a}} \tilde{a}\right]$, given that the voiced oral onset is cued by delayed nasality in the vowel. Factoring their lack of experience of this contrast being phonemic, they should at least be able to perform better in the [ $b^{a} a \tilde{]}$ $\left[m^{\tilde{a}} \tilde{a}\right]$ contrast than the $\left[\mathrm{b}^{\tilde{a}} \tilde{a}\right]-\left[m^{\tilde{a}} \tilde{a}\right]$ contrast. A perceptual experiment is currently being conducted to test this prediction.

It should be noted that, there is another dimension of the phonotactic restriction in Taiwanese that this proposal has not explicitly dealt with: the requirement to maximize the contrast between oral and nasal vowels. Analysis along this line can directly account for the lack of [ma] in Taiwanese. A Dispersion Theoretic account has been proposed to account for a similar phenomenon, namely 'environmental shielding', the alternation into or insertion of an oral segment between a nasal consonant and an oral vowel, e.g., /ma/ $\rightarrow$ [mba], so that the contrast between an oral vowel and a nasal vowel can be maximal (Stanton, 2016). In the present study, the unattested [ma] in Taiwanese is ruled out by co-articulation and a nasality-alignment constraint, without specifically referring to preserving contrast between oral and nasal vowels, although the requirement to fully nasalize a nasal vowel (using the ALIGN(NAS, EDGE, V) constraint) may be suggesting something similar to contrast maximization: the nasal vowel has to be maximally nasal in Taiwanese, but not in languages like French. A potential direction of future research along this line would be to compare the predictions made by accounts based on the contrasts of stops (the current study) or on the contrasts of vowels (the shielding account), and whether both accounts can be brought together. Concerning the last possibility, the current analysis make a prediction when considered together with the environmental shielding analysis: If shielding only appears when oral and nasal vowels must be maximally distinct from each other, and if making nasal vowels completely nasal is an important way of achieving maximal distinctiveness, the prediction is the languages with environmental shielding is less likely to have a contrast between voiced oral and nasal onsets, based on the fact in Taiwanese and my analysis.

To conclude, I have used the Taiwanese data to demonstrate how a three-component Dispersion Theoretic account can bridge the correspondence between language-specific surface phonotactics and phonetic realizations. This account also makes explicit predictions on the typology of attested surface patterns, as well as on speakers' perception of speech sounds with specific acoustic properties. Finally, the fact that the Taiwanese data can be approached from two different perspectives under the Dispersion Theory opens up more possibilities of further research that may have more general implications to the phonological theories on phonemic contrasts.

\section{References}

Ang, Uijin (2012). The Drift of Change of the Initial /j-/ of Southern Min. Journal of Taiwanese Languages and Literature $1-34$.

Chang, Yueh-chin, Feng-fan Hsieh \& Yu-lun Hsieh (2011). Phonetic Implementation of Nasality in Taiwanese (and 
French): Aerodynamic Case Studies. Proceedings of the 17th International Conference of Phonetic Sciences, 436439.

Clumeck, Harold (1976). Patterns of soft palate movements in six languages. Journal of phonetics 4:4, 337-351.

Cohn, Abigail C (1990). Phonetic and Phonological Rules of Nasalization. Ph.D. thesis, UCLA.

Delvaux, Véronique, Didier Demolin, Bernard Harmegnies \& Alain Soquet (2008). The aerodynamics of nasalization in French. Journal of Phonetics 36:4, 578-606.

Flege, James Emil (1988). Anticipatory and carry-over nasal coarticulation in the speech of children and adults. Journal of Speech, Language, and Hearing Research 31:4, 525-536.

Flemming, Edward (1996). Evidence for constraints on contrast: The dispersion theory of contrast. UCLA Working Papers in Phonology 1, 86-106.

Flemming, Edward (2002). Auditory representations in phonology. Routledge.

Flemming, Edward (2004). Contrast and perceptual distinctiveness. Phonetically-based phonology 232-276.

Flemming, Edward (2006). The role of distinctiveness constraints in phonology. Ms, MIT.

Gallagher, Gillian (2010). Perceptual distinctness and long-distance laryngeal restrictions. Phonology 27:03, 435-480.

Henke, Eric, Ellen M Kaisse \& Richard Wright (2012). Is the sonority sequencing principle an epiphenomenon. e sonority controversy 65-100.

Kawasaki-Fukumori, Haruko \& John J Ohala (1997). Alternatives to the sonority hierarchy for explaining segmental sequential constraints. Language and its ecology: Essays in memory of Einar Haugen 100, p. 343.

de Lacerda, Armando \& Brian Franklin Head (1966). Análise de sons nasais e sons nasalizados do português. Revista do Laboratório de Fonética Experimental 6, 5-70.

de Lacerda, Armando \& Peter Strevens (1956). Some phonetic observations using a speech-stretcher .

Lin, Philip T. (2015). Taiwanese Grammar: A Concise Reference. Greenhorn Media.

Lindblom, Björn (1986). Phonetic universals in vowel systems. Experimental phonology 13-44.

Lindblom, Bjorn (1988). Phonetic content in phonology. Phonologica 181-196.

Maddieson, Ian \& Sandra Ferrari Disner (1984). Patterns of sounds. Cambridge university press.

Mateus, Maria Helena Mira (1982). Aspectos da fonologia portuguesa. Lisbon: Centro de Estudos Filologicos.

Pan, Ho-hsien (2004). Nasality in Taiwanese. Language and speech 47:3, 267-296.

Parkinson, Stephen (1983). Portuguese nasal vowels as phonological diphthongs. Lingua 61:2-3, 157-177.

Stanton, Juliet (2016). Environmental shielding is contrast preservation. Ms, MIT.

Steriade, Donca (1997). Phonetics in phonology: the case of laryngeal neutralization. Ms, UCLA.

Steriade, Donca (1999). Alternatives to syllable-based accounts of consonantal phonotactics. Osamu Fujimura, Brian D. Joseph \& Bohumil Palek (eds.), Proceedings of LP '98: Item Order in Language and Speech, 205-245.

Ushijima, Tatsujiro \& Hajime Hirose (1974). Electromyographic study of the velum during speech. Journal of Phonetics 2, 315-326.

Yip, Moira (1988). The obligatory contour principle and phonological rules: A loss of identity. Linguistic inquiry 19:1, 65-100. 